\title{
MOVIMENTO INDÍGENA OU INDÍGENAS EM MOVIMENTO
}

\author{
Almires Martins Machado ${ }^{1}$
}

RESUMO: Dada a visibilidade política, que os povos indígenas vêm conquistando, novas reflexões devem ser feitas, estigmas devem ser superados, para evitar a exclusão pela diferença, cultura, cosmologia e sistema jurídico. Questionando, contestando a desigualdade social, discriminação, racismo, segregação, negação de direitos territoriais, nasce o(s) movimento(s) indígena(s). Valorizando, atualizando a "cosmoideologia étnica", formatando uma intelectualidade indígena.

Palavras-chave: Movimento indígena. Direitos. Protagonismo.

\section{INDIGENOUS MOVEMENT OR INDIGENOUS MOVEMENTS}

ABSTRACT: Given the political visibility that indigenous peoples are conquering, new reflections must be made, stigmas must be overcome, to avoid exclusion by difference, culture, cosmology and legal system. Questioning, contesting social inequality, discrimination, racism, segregation, denial of territorial rights, indigenous movement is born. Valuing, updating an "ethnic cosmoideologia", formatting an indigenous intellectuality.

Keywords: Indigenous movement. Rights. Protagonism.

\section{MOVIMIENTOS INDÍGENAS O INDÍGENAS EN MOVIMIENTO}

RESUMEN: Dada la visibilidad política, que los pueblos indígenas vienen conquistando, nuevas reflexiones deben ser hechas, estigmas deben ser superadas, para evitar la exclusión por la diferencia, cultura, cosmología y sistema jurídico. Cuestionando, la desigualdad social, discriminación, racismo, segregación, negación de derechos territoriales, nace el (los) movimiento (s) indígena (s). Valorizando, actualizando una "cosmoideología étnica", conformando una intelectualidad indígena.

Palavras Clave: Movimiento indígena. Derechos. Protagonismo.

\footnotetext{
1 Bacharel em Direito (UNIGRAN), mestre em Direitos Humanos e doutor em Antropologia pela Universidade Federal do Pará (UFPA). Professor na Pós Graduação, em historia indígena na Faculdade Brasil Amazônia (FIBRA), Belém. Endereço eletrônico: ateguara@gmail.com.
} 


\title{
AVÁ GUATAHARUPI O SEA AVÁ JEGUATÁ
}

NHE'E BYKY: Avá kuera odjekua'á, ha oipuaká política'pe, ikatuarã moarandu pyahu, hasakue djerehane, ondoikoi haguã oñemosẽa ndojojoguaiteha, arandukua'á, cosmologia, ha nhande repy; poroheka, juavyreko social, oñemboykearã, ombojehe'áva, nome'esei nhande yvy direito, upeixa onhepyrum avá guataha. Nhamombae'ete, "cosmoideologia étnica" koangaguá, oñemohenda ava iñaranduvéva.

Ayvu nhe'e: Ava guataha. Ava repy. mba'eapohára.

\section{Nhande nhe'e (nossas palavras)}

\begin{abstract}
"Caros amigos, para terminar a nossa intenção e a intenção do Mario Juruna, é que o povo brasileiro se organize. Tenhamos o direito de organizar, aproveitar aqueles elementos que amam seus irmãos. Quer a sobrevivência do seu povo, de sua raça, que aqueles que são responsáveis por nós, nos de a liberdade. Tenha a liberdade de sentar com todos os caciques indígenas do Brasil, em congresso e simpósio, em seminário, quem quer que seja, para discutir juntos, porque não adianta dizer ao doutor, que esta doendo o corte que esta no pé. $O$ doutor pode dar remédio, de acordo com minha queixa, mas a dor ele não esta sentindo, a dor ele não sente. $O$ nosso caso, jamais um branco entendera. $O$ sofrimento moral, espiritual do índio, e nos mesmo estamos diante dessa impossibilidade dos brancos sentir o nosso problema, o problema do índio".

Marçal de Souza (Relatório do I seminário de estudos indigenistas, 1980: 14-15).
\end{abstract}

Os contatos entre os povos sempre foram marcados pela inconstância e imposição por parte daquele considerado o mais forte ou do que tinha domínio de uma tecnologia diferenciada e, por vezes assustadoramente destrutiva. Nesse sentido o domínio ou o controle se dá de acordo com a cultura do vencedor, no caso das terras do novo mundo apagou as vivências e experiências dos povos indígenas (Monteiro: 2001:5-37). As suposições e conclusões as quais o dominador chega são fruto da forma como a sua cultura entende o mundo, dos princípios que valoram as suas vidas. Dessa forma, o outro, o dominado, é considerado como inferior, quando não é visto como exótico, não gente, selvagem.

Desde que o europeu desembarcou na nova terra, seu etnocentrismo (Rocha: 2007; Bonte, Pierre \& Izard: 2008: 247-248), não lhe permitiu a construção do outro como pessoa. A crença na superioridade, no modelo de civilização cristã-ocidental, não o deixava vislumbrar outra verdade que não a sua, gerando, conseqüentemente, a negação do direito do outro. Com isso se inquiria acerca da humanidade dos habitantes do novo mundo, os intelectuais da época se desdobravam em argumentações para denotar se estas pessoas possuíam direitos, alma ou se eram gente. Vistos como uma cultura incapaz, gestando a problemática jurídica de como regulamentar as relações sociais entre conquistador e conquistado. Pululavam os conflitos de interpretação sobre quem seriam os índios. Eram gente? Possuíam direitos ou não? 
Quando da criação da FUNAI em 1967, no Congresso Nacional um documento protocolado na secretaria com o titulo de "O PROBLEMA INDIGENA", narra brevemente o histórico da situação dos povos indígenas, como se segue:

EM n. 0266, de 21.09.1967, protocolo 010664 - secretaria do congresso: (...) I - O PROBLEMA INDIGENA. Quando o descobridor português aportou às plagas brasileiras, aqui encontrou os proprietários da terra dispostos ao mais generoso entendimento. Os que tiveram na caravela de Cabral rezam as crônicas, embora sem intérprete que lhes traduzisse a palavra, demonstraram por gestos da mais curiosa afabilidade, seus instintos pacíficos. Toda a famosa carta de Caminha, em se referindo aos gentios, tanto quanto à terra que lhe pareceu promissora de tal modo que "em se plantando dar-se-á nela tudo", e um elogio a aquela "gente sadia, robusta, ingênua e hospitaleira". No princípio os que ficaram, como Caramuru e João Ramalho, casando-se com filhas de caciques, sempre encontraram, da parte deles, a melhor acolhida. Mas depois, revelando-se os colonos desejosos de ter a terra em sua posse exclusiva, provocaram o ânimo nativista dos gentios e começaram as lutas, mais acesas ainda quando queriam subjugá-los para o trabalho escravo e, ante a reação libertária, classificavam-nos de bugres indolentes e viciosos. Graças aos jesuítas - que aqui vieram depois que um breve papal, na metade do século XVI, declarou os índios entre os humanos - houve reação contra as pretensões dos colonos, iniciando-se a catequese, para dilatar também a fé cristã e não apenas o império lusitano. Nomes índios como os de Poti, na guerra holandesa, Tibiriçá, Cunhambebe, Tibiriçá Tabira, Piragibe, Tomagica, estão estreitamente ligados à conquista da Bahia, de Pernambuco, do Rio de Janeiro e do Maranhão. Mas tanto mais se atiçava a cobiça dos colonizadores, na procura de terras de cultura, de pastagens naturais, de riquezas do subsolo, era o índio afastado a ferro e fogo para o interior do país, preado pelos bandeirantes, roubadas as suas mulheres, tomados violentamente os seus filhos, sem que nem sempre a proteção dos jesuítas conseguisse defendê-los suficientemente (Santos Filho:2005-21).

$\mathrm{Na}$ atualidade dada as visibilidades políticas que os povos indígenas vêm conquistando, novas reflexões devem ser feitas. Estas perpassam cada vez mais pela necessidade de se reconsiderar a maneira de pensar, a visão que a sociedade não indígena tem dos povos indígenas. Os velhos estigmas devem ser superados, para somente assim se ter novos marcos de como conceituar o outro. Os pressupostos para se pensar a questão indígena vão além das oposições entre vencedores ou vencidos, dominantes e dominados, que acabam deixando para os povos indígenas apenas dois papéis, os de vítimas de aniquilação ou de mártires da conservação da cultura (Stefanes Pacheco, 2006). 
O exercício do poder envolve todos os tipos de relações, entre elas as de ordem econômica, religiosa, social, militar, etc. Perpassa pelo modo como as pessoas vêem o mundo, de como com ele interagem, é onde todas as coisas tem significado. A cultura esta sempre em continua reinterpretação, conforme novos conhecimentos se apresentam, nos contatos com outros povos, nas relações de comercio, trocas e viagens. Se a cultura vai se lapidando ou se reinterpretando, o mesmo ocorre com as estruturas sociais, que estão em permanentes mudanças, reinterpretações, adaptações. Delineando a dualidade civilizado-primitivo, vários mal entendidos se sucederam, criando problemas sérios na relação entre quem já estava aqui e com os que chegavam de longe. Esse mal entendido permanece nos dias atuais, fortalecendo as raízes do racismo, preconceito, discriminação, injuria, que emerge de tempos em tempos com toda força, como uma patologia social, um câncer que expõe todas as agruras da construção da pessoa versadas no etnocentrismo.

Não somente pelo etnocentrismo, mas pela construção de uma alteridade que impõe os muros da separação entre o nós (civilizados) e os outros (selvagens) ou ainda em razão de uma diversidade cultural, sendo pura e simplesmente analisado sob as lentes de um exotismo cruel, sórdido, excludente. A outra forma de marcação do outro, veio pela desigualdade social e de intelecto, nós indígenas fomos o objeto da criação de uma teoria que nos colocava entre os incapazes de praticar atos civis validos, a teoria da incapacidade, razão pela qual precisávamos de tutor, segundo afirmavam os dominadores.

Dessa forma definiram-se as outras formas de excluir, seja pela diferença, cultura, cosmologia, sistema jurídico e na construção da pessoa, considerando que fomos nesse sentido, lastreados segundo pressupostos "científicos", suprimindo os nexos de uma humanidade, que precisavam ser domesticados, por não sermos evoluídos. Era, é a continuidade do genocídio e estamos convivendo com essa situação desde que o europeu pisou no chão do chamado novo mundo, trazendo "progresso". A premissa esta em questionar e contestar ideias que perfazem somente a comparação, superior-inferior, capaz-incapaz, civilizado-primitivo, igual-desigual e alegados em relação a este ou aquele povo, desta para aquela cultura. Deve-se enfatizar que há culturas diferentes e não inferiores, que não há raças superiores e nem inferiores, existe sim diferenciações entre os mais diversos povos que habitam o planeta e cada qual com sua especificidade. O que de fato se constata é o olhar etnocêntrico, que edifica um juízo de valor a partir de seus próprios valores, sendo a cultura do julgador a melhor, mais desenvolvida, perfeita, justa. 
A desigualdade social continua a erigir as barreiras raciais que se manifestam em discriminação, racismo, segregação, negação de direitos humanos inerentes à pessoa, que mesmo com previsão constitucional e criminalizadas tais atitudes, ainda é um fato real no dia a dia das minorias étnicas e socialmente desfavorecidas. Em se tratando da relação entre indígenas e os não indígenas que habitam o entorno das reservas indígenas é de constante impasse, eivadas de preconceitos, de eminente conflito, comparação entre raça superior e inferior. Todo indígena habitante de terra indígena próxima ou não de centros urbanos sofre o estigma de ser índio ${ }^{2}$, bugre ${ }^{3}$, preguiçoso, alcoólatra, tutelado, raça inferior principalmente se esta comunidade localiza-se em um Estado onde a retomada do território tradicional é uma constante, como no caso do Mato Grosso do Sul (Machado:2007). Os termos pejorativos são os mais usados para fazer menção ao indígena ou a comunidade local, na existência de conflito o etnocentrismo, o racismo campeia nos vários segmentos da sociedade dita civilizada. O preconceito e a discriminação se tornam patentes, quando sucedem eventos como, por exemplo, o fechamento de rodovias em protesto pela morte de lideranças ou quando da retomada, entrada no território considerado tradicional, sobretudo quando quem invadiu a terra indígena e está na posse da mesma, é família tradicional e de políticos. Pressupõe-se que lugar de índio é nas matas, nas aldeias, caçando, pescando, que é o que índio de "verdade" sabe fazer, e não envolvido com questões políticas que exigem cumprimento de seus direitos. Ocorre uma guerra midiática do conflito, com as mais diversas manifestações em desfavor do indígena, nos mais diversos meios de comunicação.

Embora no Brasil se creia na existência da democracia racial, considerando que não há muito tempo se imaginava o brasileiro no geral, como alguém que assimilava bem a questão da mestiçagem e as influencias dos povos africanos e indígenas que estão na formação do povo brasileiro, esse mito já vem sendo desconstruído há algum tempo por diversos autores. Não se atentou para o fato de que os povos indígenas constroem seus processos de autonomia, têm seus projetos de futuro pensados a partir de sua cosmogonia, não limitados somente pela preservação cultural, mas reivindicando espaço próprio de discussão, de sua participação na construção da nação da qual faz parte.

Penso que o conceito de autonomia se concretiza em dois momentos distintos: a) do ponto de vista legal nasce com a previsão Constitucional inserida nos textos da Constituição

\footnotetext{
${ }^{2}$ É a denominação genérica pela qual comumente os indígenas são chamados, desde que Colombo imaginou ter chegado as Índias. É usado aleatoriamente para designar qualquer pessoa que aparente ser indígena.

3 Termo pejorativo pelo qual o indígena é chamado pelos não indígenas, para demonstrar desprezo, desigualdade, inferioridade, primitivismo.
} 
Federal de 1988, em especial o art. 231, onde se insere os dispositivos basilares promovedores do princípio e do reconhecimento da autonomia. Em tela destacam-se as previsões delineadoras do reconhecimento da organização social, costumes, línguas, crenças e direitos originários sobre as terras que tradicionalmente são ocupados pelos povos indígenas. Cabendo ao Estado o dever de demarcar e proteger essas terras indígenas que pertencem à União; b) ao reconhecer e determinar o respeito à organização social e às terras de cada povo, reconhece também a pluralidade jurídica, mais que isso valida os efeitos do Direito vigente internamente, em cada comunidade. Nesse front de lutas cada povo se valerá da Constituição Federal para fazer valer o seu Direito, interpretando de acordo com os seus valores culturais e pelo que dita a sua cosmologia.

Nesse âmbito o Direito deve ser buscado nas mais diversas frentes de luta, seja no campo da saúde, alimentação, educação, proteção e preservação da natureza, dos ecossistemas e biomas quase sempre ameaçados pela ocupação desordenada do entorno das terras indígenas. O conceito de autonomia é constantemente construído e solidificado, com isso amplia o horizonte dos objetivos a serem alcançados, como por exemplo, estar mais presente nas discussões que dizem respeito a si e seus interesses futuros, estar nos ministérios para cobrar do Estado Brasileiro o respeito e o cumprimento do preceituado na norma maior. Os povos indígenas não se resignam mais a ser objeto de direito e sim reclama o protagonismo político, sua participação no momento de discutir as políticas públicas.

Tal discurso se dissocia do que é descrito sobre os povos indígenas nos livros didáticos até os dias atuais; há uma controvérsia enorme suscitada em relação à identidade dos indígenas em questão, aludindo-se a eles, classificando-os de misturados, aculturados, mestiços, paraguaios, índios de mentira, desaldeados, em razão de alguns se considerarem miscigenados, mas que não abdicou de sua identidade e pertencimento étnico.

Toda essa violência, seja física, simbólica ou psicológica, serve para negar-nos a indianidade, memória, pertencimento e cultura. Quer-se determinar ao indígena o seu "lugar", na sociedade, como subalterno, de que esta a margem do processo econômico, político, administrativo, jurídico, que são cidadãos de segunda categoria. A identidade e alteridade caminham juntas, assim como a semelhança/diferença, estão sempre se acercando de comparações entre uma cultura e outra, o que quase sempre redunda em conflitos de olhares, juízo de valores dissonantes, mesmo porque as pessoas são diferentes. Afirma Moreira (2005:27-28), que a comparação é uma imprudência metodológica, podendo se apresentar 
ingênua, enganosa e corromper o que se está observando, quando o que se quer de imediato é encontrar diferenças ou contrastes.

A discussão sobre identidade étnica passou por diversas fases no entender de Renato Athias (2007), estando resumidas em três principais correntes distintas na teoria antropológica: da fusão das raças, da aculturação e da fricção interétnica. As primeiras, concebidas pela Antropologia Cultural e a última, desenvolvida por Roberto Cardoso de Oliveira, consistente na idéia de que o contato se processa por meio de uma relação dialética contrastiva, podendo ocorrer de forma simétrica ou assimétrica. A forma pela qual o determinado indivíduo expressa e reconhece uma identidade social está em si mesmo impregnado de ideologia. Portanto, o sistema de crenças e valores encontra-se subjacente à forma pela qual discrimina o outro, considerando seu pertencimento social, étnico. É impossível para uma identidade étnica reproduzir um retrato de outra sem recorrer a seus próprios critérios absolutos, componentes de sua ideologia. Qualquer traço cultural eleito para diferenciação entre os grupos está inarredavelmente imbuído de uma carga cultural, nunca isento de parcialidade. Assim passados alguns anos da chegada do colonizador, já conhecendo as suas intenções e modo de agir, nasceram os primeiros movimento(s) indígena(s) para fazer frente à destruição de seu território, aldeias, vidas, contra a escravização, para manter sua autonomia e liberdade. Desde então muitas guerras foram travadas, confederações indígenas formatadas para combater o invasor, porem essa resistência não chegou a ser bem sucedida, em razão das muitas traições ocorridas. No entanto o espírito indígena está imbuído de uma resistência, manifestando uma resiliencia viva e cada vez mais convencido que deve se apoderar e empoderar de todos os recursos e conhecimentos possíveis, para ao menos a destruição ser menor. Conforma-se ai os moldes do movimento indígena. Somente no final do século XX, foi possível, vislumbrar um movimento indígena que desvencilha-se das ideologias nacionais que lhe foram impostas e direciona-se por um movimento que valoriza e atualiza uma "cosmoideologia étnica", pautando pela formação de uma intelligentsia nativa ou uma intelectualidade indígena.

A trajetória do movimento indígena brasileiro é orientada por uma luta de gigantes, forças desiguais, adversas, desafios, ousadia, vicissitudes e singularidades, que somente a tenacidade e a resiliencia foram capazes de alimentar essa resistência, na tentativa de viabilizar alternativas ao modo como às políticas em relação ao índio eram praticadas, de terra arrasada, genocídio, em razão das decisões estarem concentradas nas mãos de uma classe dominante, sabidamente contrarias ao interesse indígena. 
Essa caminhada foi marcada por muitas vitorias e derrotas, aprendizado, que possibilitou a maturidade para reorganizar-se, desejando uma eficiência, resultados, representatividade, mobilização, articulação, com o intuito de alcançar uma representação nacional, na tentativa de abarcar a diversidade étnica existente e de potencializar os interesses das bases. Cada região tem uma expertise em suas reivindicações, dado que com o advento da escola, muitas das lideranças são escolarizadas e boa parte delas com formação superior, esse movimento(s) indígena é que mantém agora o dialogo com as autoridades, locais, regionais, nacionais e internacionais, com pautas que defendem a autonomia, o direito a serem consultados e especialmente o protagonismo em suas demandas, pois ninguém melhor que o indígena para falar e reivindicar seus direitos e os inerentes ao seu território e povo.

Diante das omissões perpetuadas pelos agentes públicos relacionadas às questões indígenas, deixavam patentes o seu total despreparo para tratar com o diferente, diverso, que vive sob uma lógica diferenciada, por isso mesmo culturamente distante do mundo ocidental e seus valores judaicos cristãos. Portanto, as políticas públicas que seguiam as agendas de governo e não uma política de Estado passa a ser contestada, por comunidades e organizações indígenas, que exige um novo olhar, um novo juízo, um novo desenho e uma nova forma de gerir o presente e tudo que diga respeito ao futuro das aldeias. Esse movimento indígena agora com lideranças qualificadas, escolarizadas, politizadas, passa a ocupar espaços antes prioritariamente de assento de indigenistas ou especialistas em índio, por vezes contra o próprio indigenismo, portanto tinha uma nova missão agora urgente, amansar estes brancos e suas concepções ultrapassadas, ainda mais em razão de os mesmos ocuparem espaços de poder, de decisão. Precisava-se de aliados com urgência, especialmente as ONGs, embora estas em muitos casos ainda reproduzam aspectos de um colonizador tirano: "estamos aqui para ajudar, desde que seja do nosso jeito" (Luciano: 2006).

A capacidade indígena civil para praticar atos validos, somente veio consolidar-se com a Constituição Federal de 1988:

Artigo 231 - São reconhecidos aos índios sua organização social, costumes, línguas, crenças e tradições, e os direitos originários sobre as terras que tradicionalmente ocupam, competindo à União demarcá-las, proteger e fazer respeitar todos os seus bens.

Artigo 232 - Os índios, suas comunidades e organizações são partes legítimas para ingressar em juizo em defesa de seus direitos e interesses, intervindo o Ministério Público em todos os atos do processo.

Esses artigos estão aí, graças já ao movimento indígena, antropólogos e a sociedade civil, que unindo forças, conseguiram emplacar esta previsão de muitíssima valia para os 
povos indígenas. Estes, com seu movimento organizado, fazem uso dessa previsão legal para pressionar e cobrar do governo, responsabilidade, mudança de postura, atitude, empenho, uma política de estado e não de governo, no relacionamento com os povos indígenas, considerando as novas orientações jurídicas promulgadas com a Constituição Federal de 1988 e a mais recente Convenção 169 da OIT. A Tonica do dialogo agora predominante perpassa pelas ideias, princípios e conceitos que valorizam e potencializam a diversidade cultural, a promoção do diálogo intercultural, educação, cidadania, autonomia e protagonismo dos povos indígenas brasileiros.

Os habitantes do novo mundo antes entendidos como selvagens, sem alma, não humano, incapaz, tutelados, negro da terra, objeto de direito, escravo, entrave ao progresso, passou a ser considerado como sujeitos de direitos. Por estar vivendo em aldeias ou não, num mundo em constante transformação, seja no campo jurídico, educação ou novas tecnologias, os povos indígenas por meio de suas lideranças, através de suas organizações reivindicam para si o direito de conviver com o tradicional e o tecnológico e isso tem a ver somente conosco e mais ninguém, se nos vai ser prejudicial ou favorável, é por nossa conta e risco, pois alem de ser desejável é um direito.

O movimento indígena brasileiro, que nas ultimas décadas do milênio passado, cresceu, alcançou alto nível de articulação nacional e internacional, de mobilização e luta política por direitos, chamou à atenção do mundo dito civilizado para situações de violência, extermínio, genocídio, esbulho, exploração e aviltamento dos povos indígenas brasileiros, no entanto na atualidade atravessa forte crise de identidade e de capacidade de articulação, mobilização e luta. Os sinais de recuperação se apresentaram no ano passado, quando nenhum outro movimento social, avançou, conquistou espaço, obrigou políticos e governo a reverem certas ações e conseguiu sustar a aprovação de emendas a Constituição como a PEC 215 e a vigência do decreto 303 da AGU.

É notório que aquelas lideranças de um movimento reconhecidamente histórico e vitorioso, nem sempre eram escolarizadas, em contra ponto temos hoje doutores ou pósdoutores, e o movimento indígena perdeu a força de outrora, não conseguindo especialmente uma articulação intraétnica ou uma agenda de demandas e interesse comum, considerando as 325 etnias no país. Talvez seja em razão de não termos um movimento indígena nacional estruturado, temos grandes organizações indígenas que aspiram ao nacional, como foi a União das Nações Indígenas (UNI), Coordenação das Organizações Indígenas da Amazônia Brasileira (COIAB) ou nos dias de hoje a Articulação dos Povos Indígenas do Brasil (APIB). 
O que se percebe país afora, são os indígenas em movimento nas instancias governamentais, representando suas organizações locais ou mesmo regionais, com interesses comuns ou mesmo divergentes de indígenas em outras regiões do país.

Os povos indígenas não se diferem de qualquer outro povo do mundo, o ponto crucial esta em que são diferentes no modo como pensam, querem e buscam um bem viver, caminhos de superação que os conduza a autonomia, encontrando melhores condições para seus modos de vida, tradicionais ou não, aperfeiçoamento suas técnicas e potencializando suas lógicas com novos conhecimentos adquiridos com outras culturas, neste caso as sociedades não indígenas. Dessa forma, aprimoram suas estratégias de conquistas, adentrando o mundo da política no cenário local, municipal, estadual, e nacional, por meio de suas organizações, ocupando espaços de poder político, dessa forma definem, propõe, discutem, analisam, reformulam em que condições esperam resultados nas negociações políticas e econômicas com o Estado brasileiro.

\section{Pahapê (finalmente)}

Não basta o reconhecimento da diferença, é necessário prover formas de coexistência dentro da alteridade: A idéia do relativismo, multiculturalismo, direitos humanos, remete às identidades coletivas na perspectiva da construção de novos paradigmas que de fato construa a cidadania, considerando o reconhecimento da diferença e do direito à diferença. Para tanto é preciso alargar os caminhos que promovam os direitos, identidades e cidadania. O desrespeito ao modo de ser, dos povos indígenas, o não reconhecimento do mesmo como sujeito de direito por grande parcela da sociedade nacional, não impede que esta venha a ser uma posição a ser conquistada. Mesmo que boa parte das ações promovidas em terra indígena, não tenha levado em conta as especificidades do saber local da comunidade, não respeitando o modo de ser do indígena, a sua cosmovisão, todas essas ações servem de lição para que o erro não se repita.

O indígena é um ser humano como outro qualquer, como tal tem os seus direitos e quer exercer a sua cidadania, não fosse assim, não teria defendido esta terra contra holandeses, franceses, paraguaios, juntamente com os negros derramaram o seu sangue para hoje ter as suas raízes fincadas no solo da pátria amada, esta não é exatamente como uma mãe gentil, mas o brado retumbante dos povos indígenas ecoa por direitos e reconhecimento como ser diferente, que quer tão somente viver em paz, na terra que o viu nascer e crescer; terra da sua origem, de suas narrativas, da sua identidade, dos seus heróis. 
É preciso que se tenha em mente que mesmo o indígena histórico sempre foi um sujeito atuante, mesmo sendo invisibilizado como filho da nação brasileira, pelo qual derramou sangue em guerras, permitindo que hoje o país tenha o atual desenho de fronteiras. Sempre foi capaz de tomar decisões em defesa de seus direitos, ainda que fosse necessário pegar em armas. Jamais deixou de costurar alianças, redes de conhecimentos contrapondo-se a opressão, escravização, exploração e buscando o limiar de seus direitos. Nunca foi uma vitima passiva. Cada vez mais os indígenas se qualificam e se apresentam no cenário nacional e internacional, como protagonistas de seus direitos e de sua historia; continuam negociando, reivindicando, formatando resistências, propondo soluções a problemas históricos vividos pelos mesmos, quando não são os agentes que denunciam o expresso desrespeito pelos direitos humanos indígenas fomentados pelo Estado brasileiro e seus agentes.

É nesse o contexto que o movimento indígena atual tenta se fortalecer, tentando escapar das cooptações/influencias partidárias, acadêmicas, políticas, econômicas, epistêmicas, ideológicas, não se furtando aos problemas e problematizações relacionadas ao tradicional, cientifico, moderno, étnico, pertencimento, interpretações, tramas sociais na hibridização onde não cabe mais razão em ver ou buscar cultura supostamente pura. $O$ velho e o novo convivem nas reservas/terras indígenas, a teia de significados enreda-se no saber local (GEERTZ, 1998), dando forma, fluidez, porosidade, permeabilidade, flexibilidade as fronteiras culturais, reinterpretando, ressignificando, reelaborando a cultura, rede social, modo de pensar, ver e agir, conforme a situação o exigir, legitimando-a. Não está passivo, não aceitando o papel de vitimas, o paradigma da aculturação, de visões estereotipadas, de sujeitos de segunda categoria, de incapaz; o século XXI, permite ir muito mais alem do imaginado, tanto que o "índio de verdade", hoje esta nas universidades, é doutor, pós-doutor, faz parte das redes sociais da internet, twitando e trocando informações via facebook e watsapp.

As palavras pronunciadas pela liderança indígena Ailton Krenak resume este artigo:

"No mundo todo ainda existem povos tradicionais, na África, na Ásia, Norte da Europa, Norte America, não importa o quanto estejamos afastados dos grandes centros urbanos, temos que responder a tantas perguntas que incluem desde a escola, saúde administração de terras, negócios com terceiros....Basta esta lista para exemplificar o quanto estamos sendo intimados a criar novas respostas para um grande numero de perguntas nem tão novas assim" (BRASIL/RCNEI, 1998, p.23).

Novas respostas são cobradas a cada instante em que indígenas se levantam e contestam as situações que estão postas, sem contudo serem tão novas, como atesta Krenak; o multiculturalismo, o pluralismo jurídico, a diversidade, a alteridade, a cosmologia, a lógica de 
mundo, continuarão a provocar inquietações, enquanto o relativismo não for uma pratica, considerando que o universalismo jurídico foi e continua sendo uma imposição. Ainda mais no governo de Michel Temer, onde tudo está uma desordem em progresso, um achacamento completo dos direitos indígenas, patrocinados pelas bancadas da bala, bíblia, agronegócio e mineradoras. Os povos indígenas continuam com sua marcha rumo a conquistas e implementação de direitos, mesmo que a intolerância se intensifique, não será diferente dos velhos tempos, contudo novas armas estão sendo manuseadas e muito mais potentes no seu alcance do que o velho arcabuz ou o arco e a flecha. Que o digam as mídias sociais.

3. Kuatiá Nhe'e (Referências bibliográficas)

BONTE, Pierre \& IZARD, Michel. 2008. (direção) "Ethnocentrisme" (verbete) In Dictionaire de l'ethnologie et de l'anthropologie. Paris, Quadrige/PUF, 247-248.

CLASTRES, Héléne. 1978. Terra sem mal: o profetismo Tupi-Guarani. São Paulo: Brasiliense.

GEERTZ, Clifford. [1983], 2000. Saber local. Novos ensaios em antropologia interpretativa. São Paulo, Editora Vozes.

LUCIANO, G. J. S. 2006. Projeto é como branco trabalha. As lideranças que se virem para nos ensinar. Dissertação de Mestrado em Antropologia Social. Brasília: UNB.

2006. O Índio Brasileiro: o que você precisa saber sobre os povos indígenas no Brasil de hoje. Brasília: Ministério da Educação, Secretaria de Educação Continuada, Alfabetização e Diversidade; LACED/Museu Nacional.

MACHADO, A. M. 2007. De incapaz a mestrando. Tellus, ano 7, n. 13, pp. 155-161.

MONTEIRO, John Manoel. 2001. Tupis, tapuias e historiadores. Estudos de historia indígena e historiadores. Tese de livre docência, departamento de antropologia. IFCHUNICAMP.

MOREIRA, Manoel. 2005. La cultura jurídica guarani. CEDEAD.

NIMUENDAJU, Curt. 1987. As lendas da criação e destruição do mundo como fundamentos da religião dos Apapocúva-Guarani. Tradução por Charlotte Emmerich; Eduardo B. Viveiros de Castro. São Paulo: HUCITEC; Editora da Universidade de São Paulo.

OLIVEIRA, Roberto Cardoso de. 1976. Identidade, etnia e estrutura social. São Paulo: Livraria Pioneira Editora.

PIMENTEL, Spensy. 2012. Elementos para uma teoria política Kaiowa e Guarani. Tese de doutorado. Faculdade de Filosofia, Letras e Ciências Humanas, da Universidade de São Paulo. São Paulo. 
Relatório do I Seminário de Estudos Indigenistas. Campo Grande, 1980. Arquivo do Centro Documentação Regional da Universidade Federal da Grande Dourados (UFGD).

ROCHA, Everardo. 2007. O que é Etnocentrismo. São Paulo, Brasiliense.

SANTOS FILHO, Roberto Lemos dos. 2005. Apontamentos sobre o direito indigenista. Curitiba: Juruá.

SCHADEN, Egon. 1969. Aculturação indígena. São Paulo: Editora da USP.

SHWARCZ, Lilia Moritz. 1993. O espetáculo das raças: cientistas instituições questão racial no Brasil (1870-1930). São Paulo: Companhia das Letras.

SOUZA LIMA, A. C. 1995. A conquista como modalidade de guerra. In: Um grande cerco de paz: poder tutelar, indianidade e formação do Estado no Brasil. Petrópolis, Rj: Vozes.

. 2002. "Diversidade cultural e política indigenista no Brasil” In Tellus. n”.3, p. 04.

STEFANES PACHECO, Rosely A. 2006. Direito Indígena: da pluralidade cultural a pluralidade jurídica. In: Revista Tellus, Núcleos de Estudos e Pesquisas das Populações Indígenas- NEPPI, ano 6, número 11, outubro/2006, Campo Grande: UCDB.

VIVEIRO DE CASTRO, Eduardo. 2002. Perspectivismo e multinaturalismo na América indígena. In "A inconstância da alma selvagem e outros ensaios de antropologia". São Paulo: Cosac \& Naify, (Cap. 7 pp. 345-400)

WAGNER, Roy. 2010 b. A invenção da Cultura. São Paulo: Cosac Naif. 